\title{
DAMPAK PERUBAHAN ORGANISASI PEMERINTAH TERHADAP KOMUNIKASI ORGANISASI
}

\author{
'Bayu Amengku Praja \\ 'Program Studi IImu Perpustakaan Fakultas IImu Administrasi Universitas Brawijaya \\ bayuamengku@ub.ac.id \\ Malang, Indonesia
}

\begin{abstract}
This study aims to see the impact of organizational change on communication organization, organizational climate, and organizational commitment on organizational perfomance within the Ministry Research Technology and Higher Education. Change of organization can have an impact on communication organization. This research uses research methods qualitative and post-positivist approaches. Respondent research as many as eleven sources consisting of eight resources persons are Kemenristekdikti employees and three sources outside of stakeholders. There is also a vision and mission from Kemenristekdikti as a reference for various work activities. As a consequence of the elaboration of this vision and mission, required planning and implementation of strategic steps a structured and measurable incorporation of Kemenristekdikti. In this case organizational communication is an aspect important in organizational change to produce a good working relationship with fellow employees. Because organizational communication can form a climate organizational communication, which will have an impact towards organizational commitment that also delivers impact on organizational performance.
\end{abstract}

\section{Keywords: Climate Organization; Kemenristekdikti; Organizational Communication; Organizational Commitment; Organizational Performance}

\begin{abstract}
Abstrak
Penelitian ini bertujuan untuk melihat dampak perubahan organisasi terhadap komunikasi organisasi, iklim organisasi, dan komitmen organisasi terhadap kinerja organisasi di lingkungan Kemenristekdikti. Perubahan organisasi dapat memberikan dampak terhadap komunikasi organisasi. Penelitian ini memakai metode penelitian kualitatif dan pendekatan post-positivist. Responden penelitian sebanyak sebelas narasumber yang terdiri dari delapan narasumber pegawai Kemenristekdikti dan tiga narasumber luar stakeholders. Terdapat juga visi dan misi dari Kemenristekdikti sebagai acuan berbagai kegiatan kerja. Sebagai konsekuensi dari penjabaran visi dan misi ini, diperlukan perencanaan dan implementasi langkah strategis penggabungan Kemenristekdikti yang terstruktur dan terukur. Dalam hal ini komunikasi organisasi merupakan suatu aspek penting di dalam perubahan organisasi untuk menghasilkan suatu hubungan kerja yang baik sesame pegawai. Karena komunikasi organisasi dapat membentuk suatu iklim komunikasi organisasi, yang nantinya akan berdampak terhadap komitmen organisasi yang juga memberikan dampak terhadap kinerja organisasi.
\end{abstract}

Kata Kunci: Kemenristekdikti, komunikasi organisasi, iklim organisasi, komitmen organisasi, kinerja organisasi

Open Access at:http://ojs.uho.ac.id/index.php/PUBLICUHO/index

Journal Publicuho is licensed under a Creative Commons Attribution 4.0 International License. 


\section{PENDAHULUAN}

Dengan adanya perubahan organisasi pada Kemenristekdikti dapat memberikan dampak terhadap komunikasi organisasi. Komunikasi organisasi merupakan sesuatu yang penting, agar dapat memudahkan setiap organisasi dalam melaksanakan tujuan yang sudah ditetapkan. Menurut Pace \& Faules (2001) dalam perkembangannya setiap organisasi mengalami perubahan dan evolusi dalam rangka meningkatkan efisiensi dan efektifitasnya untuk mencapai tujuan dari organisasi tersebut. Dalam proses revolusi dan perubahan dalam suatu organisasi, keterlibatan setiap individu yang menjadi bagiannya sangatlah penting dan memiliki peran dalam kemajuan organisasi tersebut.

Komunikasi dalam organisasi merupakan sesuatu yang penting untuk membina suatu hubungan kerja antar pegawai. Komunikasi internal menurut Lawrence D. Brenman (dalam Effendy, 1997:122-129) suatu komunikasi yang efektif atau tidaknya tergantung dari penyampaian sebuah pesan komunikasi atau perintah antara pegawai, baik antara atasan dengan bawahan (downward communication), maupun antara yang jabatannya setara (upward communication) di dalam suatu organisasi, sebuah komunikasi sangat menentukan untuk menjalin kerjasama yang baik dalam organisasi tersebut. Komunikasi yang telah berjalan dengan baik dapat mendukung kemajuan organisasi tersebut. Tapi sebaliknya jika komunikasi dalam organisasi ada masalah, maka tentu saja dapat menjadi hambatan dalam tujuan dan visi misi dalam organisasi tersebut.

Dalam Goldhaber (1986:14), sebuah komunikasi organisasi dapat dinyatakan sebagai suatu proses dalam menciptakan atau bertukar pesan di dalam suatu jaringan komunikasi yang saling bergantung antara satu dan lainnya dalam menjalani suatu lingkungan yang berubah-rubah. Komunikasi organisasi memiliki peran penting dalam menyatukan suatu fungsi manajemen dalam suatu organisasi, yaitu: 1. Menentukan dan menginformasikan tujuan perusahaan; 2. menyusun suatu rencana di dalam mencapai tujuan organisasi yang ditetapkan; 3. melakukan pengorganisasian pegawai serta sumber daya yang lain dengan efektif; 4. Membuat dan menciptakan sebuah iklim organisasi yang dapat menimbulkan motivasi pegawai untuk dapat menciptakan suatu kontribusi; 5. Membuat dan dapat menciptakan suatu prestasi.

IKlim Komunikasi Dalam Organisasi merupakan persepsi dari masing-masing anggota organisasi terhadap yang ada di dalam organisasi tersebut (Goldhabar, 1992:63). Seluruh komunikasi yang terjadi di antara mereka baik horizontal maupun vertical atasan dengan bawahan dan sebaliknya dapat menambah pengetahuan dan pemahaman bagi masingmasing anggota organisasi dalam sikap maupun perilaku masing-masing anggota organisasi tersebut.

Hubungan dalam organisasi tersebut baik yang terjadi secara langsung ataupun tidak langsung dapat berdampak terhadap pertumbuhan organisasi, demikian yang terjadi 


\section{Journal Publicuho}

ISSN2621-1351 (online), ISSN 2685-0729 (print)

Volume 4 Number 2 (May-July), (2021)pp. 217-224

Accredited SINTA SK.NOMOR 28/E/KPT/2019

Open Access at:http://ojs.uho.ac.id/index.php/PUBLICUHO/index

DOI: 10.35817/jpu.v4i2.17700

engan perilaku anggota organisasi yang secara positif maupun negative, kumpulan tersebut menunjukkan adanya suatu iklim organisasi.

Komitmen Organisasi menurut Greenberg dan Baron (1993), seorang pegawai yang mempunyai komitmen dalam suatu organisasi yang lebih luas adalah pegawai yang jauh lebih stabil dan juga lebih produktif yang juga tentu saja lebih hal tersebut dapat memberikan keuntungan bagi organisasi tersebut.

Menurut Mowday, Porter, dan Steers (1982), pegawai yang mempunyai komitmen dalam organisasi yang lebih tinggi dan lebih lebih termotivasi pegawai tersebut akan berusaha lebih terhadap pencapaian tujuan organisasi tersebut.

Sehingga dapat dikatakan bahwa komitmen organisasi sangat berkaitan dengan pegawai yang memiliki suatu motivasi yang tinggi dalam berbagi dan berkorban untuk organisasi.

Kinerja organisasi merupakan salah satu cerminan dalam keberhasilan sebuah organisasi, dan juga merupakan sebuah hasil yang telah dicapai oleh para anggota organisasi. Kinerja juga dapat di kriteriakan sebagai suatu capaian dari sebuah proses tertentu yang telah dilakukan para semua anggota organisasi.

Berikutnya, kinerja juga dapat dikatakan adalah sebuah hasil dari rangkaian seluruh proses aktifitas organisasi yang telah dilakukan untuk dapat mencapai tujuan tertentu bagi organisasi tersebut. Dalam organisasi, kinerja merupakan sebuah hasil dalam kerjasama dari aktifitas para anggota organisasi dalam mencapai sebuah tujuan organisasi tersebut.

Dalam hal ini itu penulis berkeinginan untuk meneliti dengan judul Dampak Perubahan Organisasi Pemerintahan Terhadap Komunikasi Organisasi studi kasus di Kementerian Pendidikan Tinggi, Riset dan Teknologi, Kedeputian bidang Relevansi dan Produktivitas Iptek (IImu Pengetahuan dan Teknologi). Adapun tugas yang diemban oleh para pegawai di Kedeputian Bidang Relevansi dan Produktivitas Iptek (IImu Pengetahuan dan Teknologi) yaitu mempersiapkan sebuah rumus kebijakan dan koordinasi pelaksanaan dalam kebijakan pada bidang relevansi dan produktivitas Iptek (IImu pengetahuan dan teknologi).

\section{METODOLOGI}

Peneliti pada penelitian ini mengumpulkan data primer dan juga data sekunder dimana teknik pengumpulan melalui sebuah wawancara yang mendalam dan melalui studi pustaka dan dokumentasi. Keterbatasan dalam penelitian, peneliti memiliki keterbatasan, yaitu: (1) Ketika melakukan suatu wawancara tentu saja rentan terjadinya bias informasi yang dapat ditimbulkan oleh pertanyaan apabila dalam penyusunan terdapat hal yang kurang baik; (2) Peneliti tidak mengantisipasi kesiapan dari masing-masing narasumber ketika pada saat di wawancara; (3) Dapat terjadinya kemungkinan narasumber menjawab dan memberikan jawaban yang hanya ingin didengar oleh peneliti. 


\section{HASIL DAN PEMBAHASAN}

Visi dan Misi Organisasi berdasarkan hasil dari interpretasi data dalam penelitian, bisa disimpulkan tidak seluruh pegawai Kemenristekdikti sudah mengetahui dengan pasti mengenai Visi dan Misi dari Kemenristekdikti.

Komunikasi Organisasi Komunikasi Internal, berdasarkan hasil interpretasi data pada penelitian ini, dapat disimpulkan komunikasi vertikal dan horizontal sesama pegawai Kemenristekdikti dapat meningkatkan efektifitas dan efisiensi pelaksanaan tugas. Komunikasi Eksternal, berdasarkan hasil interpretasi pada penelitian ini, dapat disimpulkan komunikasi antara Kemenristekdikti dengan pihak luar, begitu pula komunikasi antara pihak luar dengan Kemenristekdikti sudah berjalan dengan baik.

Iklim Organisasi Supportiveness, berdasarkan hasil interpretasi data pada penelitian ini, dapat disimpulkan iklim komunikasi yang ada di dalam lingkungan Kemenristekdikti sudah sangat baik dan mendukung di dalam kegiatan kerja yang sedang berlangsung bagi para pegawai Kemenristekdikti. Participation, berdasarkan hasil interpretasi data pada penelitian ini, dapat disimpulkan bahwa partisipasi masing - masing dari pegawai Kemenristekdikti sudah berjalan dengan baik terhadap tugas pokok dan fungsi kerja masing - masing pegawai. Trust, Confidence, Credibility, berdasarkan hasil interpretasi data pada penelitian ini, dapat disimpulkan bahwa kepercayaan bagi masing - masing pegawai Kemenristekdikti sudah berjalan dengan baik dan harmonis. Opennes and Candor, berdasarkan hasil interpretasi data pada penelitian ini, dapat disimpulkan bahwa keterbukaan dan keterusterangan antara sesama pegawai Kemenristekdikti, Kemenristekdikti dengan pihak luar sudah berjalan dengan baik. High Performance Goals, berdasarkan hasil interpretasi data pada penelitian ini, dapat disimpulkan masing - masing anggota pegawai Kemenristekdikti mempunyai tujuan performa yang tinggi terhadap masing - masing kegiatan yang sedang dilaksanakan, begitu juga kegiatan kerjasama dengan pihak luar

Komitmen Organisasi, Komitmen Sikap, berdasarkan hasil interpretasi data pada penelitian ini, dapat disimpulkan komitmen sikap dari pegawai Kemenristekdikti sudah sangat tinggi terhadap loyalitas mereka bagi Kemenristekdikti itu sendiri dan bagi pekerjaan yang sedang mereka laksanakan. Komitmen Tingkah laku, berdasarkan hasil interpretasi data pada penelitian ini, dapat disimpulkan komitmen tingkah laku dari pegawai Kemenristekdikti dapat dilihat sangat baik dengan melihat ketika melaksanakan kerjasama kegiatan dengan pihak luar sudah sangat baik.

Kinerja Organisasi, Keluaran (Output) berdasarkan hasil interpretasi data pada penelitian ini, dapat disimpulkan bahwa hasil keluaran yang diberikan oleh pegawai Kemenristekdikti sudah sangat baik dan dapat dirasakan langsung oleh masyarakat dari seluruh kegiatan yang sudah dilaksanakan ataupun yang akan dilaksanakan baik itu juga ketika kerjasama dengan kegiatan oleh pihak luar. Hasil, berdasarkan hasil interpretasi dalam penelitian ini, 


\section{Journal Publicuho}

ISSN2621-1351 (online), ISSN 2685-0729 (print)

Volume 4 Number 2 (May-July), (2021)pp. 217-224

Accredited SINTA SK.NOMOR 28/E/KPT/2019

Open Access at:http://ojs.uho.ac.id/index.php/PUBLICUHO/index

DOI: 10.35817/jpu.v4i2.17700

dapat disimpulkan sebuah kesimpulan bahwa dari seluruh kegiatan yang sampai saat ini sudah dilakukan oleh pegawai Kemenristekdikti ataupun yang telah dilaksanakan oleh pihak luar maupun kegiatan - kegiatan yang dilaksanakan oleh pihak Kemenristekdikti itu sendiri telah memberikan efek yang positif terhadap masyarakat. Kaitan Usaha dengan Pencapaian berdasarkan hasil interpretasi data pada penelitian ini, dapat disimpulkan usaha dengan pencapaian oleh seluruh pegawai Kemenristekdikti sudah sangat efisiensi terhadap seluruh kegiatan yang dilaksanakan, baik itu dengan pihak luar maupun kegiatan yang berlangsung di dalam Kemenristekdikti itu sendiri. Informasi Penjelas, berdasarkan hasil interpretasi data pada penelitian ini, dapat disimpulkan pegawai Kemenristekdikti sudah mempunyai informasi yang jelas terhadap seluruh pelaksanaan kegiatan yang sedang berlangsung, ataupun yang akan berlangsung baik itu dengan pihak luar ataupun kegiatan yang dilaksanakan di dalam Kemenristekdikti itu sendiri

Dari hasil penelitian, berdasarkan hasil interpretasi data penelitian, dapat dirumuskan bahwa analisa dampak dari komunikasi organisasi, terhadap iklim komunikasi organisasi dan komitmen organisasi yang nantinya akan dapat meningkatkan kinerja organisasi dari Kemenristekdikti khususnya pada Kedeputian Bidang Relevansi dan Produktivitas Iptek (IImu Pengetahuan dan Teknologi), sehingga nantinya implementasi dari perbaikan dalam komunikasi organisasi, perbaikan dalam iklim komunikasi organisasi dan komitmen organisasi dapat meningkatkan hasil kinerja organisasi di Kemenristekdikti di dalam mencapai Visi dan Misi dari Kementerian yang bisa berdampak bagi kemajuan pengembangan Iptek untuk masyarakat Indonesia secara luas.

Dalam upaya mencapai tujuan dalam peningkatan kinerja organisasi, manajemen di dalam komunikasi organisasi mampu mengatasi permasalahan yang terjadi di dalam komunikasi organisasi internal, seperti kemampuan dalam meminimalisir perbedaan persepsi dalam penyampaian informasi. Selain itu manajemen komunikasi organisasi internal juga memiliki peran penting dalam penciptaan suatu iklim organisasi yang kondusif sehingga akan tercipta suatu hubungan yang harmonis diantara semua anggota.

Secara khusus, dalam suatu hubungan di antara komunikasi organisasi lalu iklim organisasi juga komitmen organisasi, dan hubungan diantara komitmen organisasi dengan kinerja organisasi, hubungan tersebut lebih kuat dibandingkan dengan hubungan diantara komunikasi organisasi dengan kinerja organisasi secara langsung. Meskipun terdapat juga beberapa hubungan diantara komunikasi organisasi dengan iklim organisasi, dan diantara komunikasi organisasi dengan komitmen organisasi, dan komitmen organisasi dengan kinerja organisasi, dan juga hubungan langsung diantara komunikasi organisasi dengan kinerja organisasi itu sendiri. Kinerja organisasi pada Kemenristekdikti khususnya Kedeputian Bidang Relevansi dan Produktivitas Iptek, tidak hanya dipengaruhi oleh komunikasi organisasi, namun juga dipengaruhi oleh iklim 
organisasi dan komitmen organisasi. Sehingga dengan adanya mediasi iklim organisasi dan komitmen organisasi akan dapat memperkuat hubungan komunikasi organisasi dengan kinerja organisasi.

Selanjutnya, terdapat beberapa faktor yang dapat menghambat upaya peningkatan kinerja organisasi pada Kemenristekdikti. Antara lain, terdapat perbedaan pemahaman antara pegawai satu dengan yang lainnya terhadap pemahaman visi dan misi dari Kemenristekdikti. Pencapaian informasi terkadang hanya berlangsung kepada beberapa pegawai saja, tidak secara keseluruhan. Sehingga dapat terjadi kesalahpahaman (misunderstanding) dalam menyelesaikan masalah yang terjadi. Terdapat perbedaan antara masing - masing pegawai terhadap komitmen kerja pegawai Kemenristekdikti yang nantinya dapat memberikan dampak terhadap kinerja organisasi.

\section{KESIMPULAN}

Secara umum dapat disimpulkan dari hasil penelitian dilapangan yang didasari oleh hasil analisa dan interpretasi, maka dapat ditarik kesimpulan bahwa dampak perubahan organisasi adalah upaya dari suatu oganisasi di dalam tujuan mencapai kinerja sebuah organisasi yang tentu jauh lebih baik. Hal ini menekankan perlunya suatu cara baru dalam meningkatkan kinerja organisasi dan seluruh anggota dalam organisasi tersebut. Komunikasi Organisasi memiliki peran strategis dalam mendukung keberhasilan implementasi peningkatan kinerja organisasi pada Kemenristekdikti.

\section{DAFTAR PUSTAKA}

A. Dale, Timpe. 1999. Seri Manajemen Sumber Daya. Yogyakarta: Gramedia.

Alo Liliweri. 1997. Sosiologi Organisasi. PT. Citra Aditya Bakti, Bandung.

Alston, Margaret \& Bowles, Wendy. (2003). Research for Social Workers: An Introduction to Methods (2nd Ed.). Australia: Allen \& Unwin.

Anwar Arifin. 1995. IImu Komunikasi. PT. Raja Grafindo Persada, Jakarta

Arni Muhammad, Komunikasi Organisasi, Bumi Aksara, Jakarta, 1995

Broom, G., \& Dozier, D. (1990). Using Research in Public Relations. Upper Saddle River, NJ: Prentice Hall.

Buchanan, B. (1974). Building Organizational Commitment: The Socialization of Managers in Work Organizations. Administrative Science Quarterly, 19, 533-546.

Cresswell, John. W. (2007). Qualitative Inquiry and Research Design, Second Edition, California: Sage Publication.

Cushway. B. \& Lodge. D. 1993. Perilaku dan Desain Organisasi. PT. Elex Media Komputindo: Jakarta.

Davis, Keith, Human Relation at Work, Tokyo: McGraw Hill Book Co, 1962.

Denzin, N.K., \& Lincoln, Y.S. (Eds.).(1994). Handbook of qualitative research. Newbury Park, CA: Sage. 


\section{Journal Publicuho}

ISSN2621-1351 (online), ISSN 2685-0729 (print)

Volume 4 Number 2 (May-July), (2021)pp. 217-224

Accredited SINTA SK.NOMOR 28/E/KPT/2019

Open Access at:http://ojs.uho.ac.id/index.php/PUBLICUHO/index DOI: 10.35817/jpu.v4i2.17700

Drucker, Peter. F. 1982. Pengantar Manajemen. Jakarta: PT Pustaka Binaman Pressindo.

Edgar Schein. 2004.Organizational Culture and Leadership, San Fransisco: The Jossey Bass.

Effendy, Onong Uchjana. 1993. Dimensi - Dimensi Komunikasi. Alumni, Bandung.

Effendi, Onong Uchjana. 1993. IImu, Teori dan Filsafat Komunikasi. PT. Citra Aditya Bakti, Bandung.

Effendi, Onong Uchjana. 2000. IImu, Teori dan Filsafat Komunikasi. Bandung : Penerbit PT. Citra Aditya Bakti.

Effendi, Onong Uchjana. 2002. Ilmu, Teori dan Filsafat Komunikasi. Bandung : Penerbit PT. Citra Aditya Bakti.

EM Griffin, 2003, A First Look at Communication Theory, McGrraw - Hill Companies

Fiedler, Fred E. (1967) A Theory of Leaderships Effectiveness, New York: Mc.Graw-Hill Book.

Fremont. E. Kast \& James. E. Rosenzweig. 1985. Organization and Management: A Systems and Contingency Approach. McCgraw Hill Series College.

Furtwengler, Dale, Penilaian Kinerja, Yogyakarta: Penerbit Andi, 2002.

Goldhaber, Gerald, M., Organizational Communication, WCB Publisher, Dubuque, low, Fifth Edition, 1990.

Greenberg, J., \& Baron, R.A. (1993). Behavior in organizations: Understanding and managing the human side of work (5th Ed), Upper Saddle River, NJ: Prentice Hall.

Guba, E.G., \& Lincoln, Y.S. (1988). Do Inquiry paradigms imply inquiry methodologies? In D.M. Fetterman (Ed.), Qualitative approaches to evaluation in education (pp.89 - 115). New York: Praeger.

Hovland, Carl. I. "Sosial Communication" dalam Bernard Berelson \& Moris

Rasberry, Robert W \& Lemoine, Laura F, Effective Managerial Communication, Kent Publishing Co, Boston, 1986.

Katz, D., \& Kahn, R.L. 1966, The social psychology of organizations, New York: Wiley.

Lasswell. Harold. 1972. "The Structure and Function of Communication In Society." Pp 117 130 in Wilbur Schramm (Ed), Mass Communications.Chicago, IL: University of Illinois Press.

Lindlof, T.R., \& Taylor, B. C. (2002). Qualitative communication research methods (2nd ed.). Thousand Oaks: Sage.

Malayu, S.P. 1997. Manajemen Sumber Daya Manusia. Bumi aksara. Jakarta.

Meyer, J.P \& Allen, N.J. (1997). Commitment in the workplace: Theory, Research, and Application Thousand Oaks, CA: Sage Publication, Inc.

Miftah Thoha, Perilaku Organisasi: Konsep Dasar dan Aplikasinya, PT Raja Grafindo Persada, 1996.

Miles, B.B., \& A.M. Huberman. (1992). Analisa Data Kualitatif, UI Press Jakarta.

M. Rogers, Everet, Communication in Organization. New York : Gramedia, 2005.

Muhammad, Arni, 1995. Komunikasi Organisasi, Bumi Aksara, Jakarta.

Muhammad, Arni, 2007. Komunikasi Organisasi, Bumi Aksara, Jakarta.

Nawawi, H. Hadari, Manajemen Sumber Daya Manusia, Penerbit Gajah Mada University Press, Yogyakarta, Tahun 1997, Halaman 89 
Nitisemito, A.S. 1982. Manajemen Personalia. P.T Gramedia, Jakarta.

Notoatmodjo. S. 2003. IImu Kesehatan Masyarakat. Rineka Cipta, Jakarta.

Onong Effendy, 1994, Ilmu Komunikasi : Teori dan Praktek, Bandung : Remaja Rosdakarya

Pace, R Wayne, \& Boren, Rober R. 1973. The Human Transaction. Glenview, III: Scott, Foresman.

Pace, R Wayne dan Faules Don F. 2006. Komunikasi Organisasi. Bandung: PT. Remaja Rosdakarya

Pandji Anoraga \& Sri Suyati, Perilaku Keorganisasian, PT Dunia Pustaka Jaya, Jakarta, 1995.

Prawirosentono. S, 1999. Manajemen Sumber Daya Manusia, Kebijakan Kinerja karyawan. BPFE, Yogyakarta.

Purwanto, Djoko. 2006. Komunikasi Bisnis. Jakarta : Erlangga.

Randall S. Schuler \& Susan E. Jackson, 1997. Manajemen Sumber Daya Manusia Menghadapi Abad 21. Erlangga: Jakarta.

Redi Panuju. 2001. Komunikasi Organisasi. Yogyakarta: Pustaka Pelajar.

Robbins, Stephen P. \& Judge, Timothy A. 2008. Perilaku Organisasi (Edisi 12, Buku2). Terjemahan Diana Angelica, Ria Cahyani, dan Abdul Rosyid. 2008. Jakarta: Penerbit Salemba Empat.

Robbins, Stephen P, Perilaku Organisasi, Erlangga, Jakarta, 1993.

Sendjaja, S Djuarsa. 1994, Teori Komunikasi. Pusat Penerbitan Universitas Terbuka

Simamora, H. 1995. Manajemen Sumber Daya Manusia. STIE YPKN, Jakarta.

Staw, B.M, \& Salancik, G.R. (1977). New Directions in organizational behavior. Chicago: St. Clair Press.

Strauss, A. \& Corbin, J. (1998), Basics of Qualitative Research : Techniques and Procedures for Developing Grounded Theory, Thousand Oaks, CA : Sage Publications.

Sutopo, H. B. (1988). Konsep-konsep Dasar dalam Penelitian Kualitatif. Surakarta: Universitas Sebelas Maret.

Taliziduhu Ndraha, Budaya Organisasi, PT Rineka Cipta, Jakarta, 1997.

Tubbs, Stewart L. - Moss, Sylvia, Human Communication : Konteks - Konteks Komunikasi, Bandung : PT Remaja Rosdakarya, 2005, h. 170.

Walker, Robert. Applied Qualitative Research, (Vermont : Gower Publishing Company, 1985).

Wirawan. 2009. Evaluasi Kinerja Sumber Daya Manusia "Teori, Aplikasi dan Penelitian". Jakarta: Salemba Empat.

Wiryanto, Komunikasi Organisasi, Jakarta : Gramedia, 2005.

Wutun, R.P. 2001. "Persepsi Karyawan tentang Perilaku Kepemimpinan Atasan. Suatu Kajian Teori Transformasional-Transaksional"; dalam Sjabadhyni, B., Graito, B.K, \& Wutun, R.P. Pengembangan Kualitas SDM dari Perspektif PIO. Jakarta : Bagian Psikologi Industri dan Organisasi Fakultas Psikologi Universitas Indonesia. 